\title{
Urbanization Process and Variation of Energy Budget of Land Surfaces
}

\author{
Ciro Gardi ${ }^{* 1}$, Nicola Dall'Olio², Maria Chiara Cavallo \\ ${ }^{1}$ Dipartimento di Scienze Ambientali, Università di Parma \\ Parco Area delle Scienze 33/A, 43100 Parma, Italy \\ ${ }^{2}$ Provincia di Parma, Servizio Agricoltura, Piazzale Barezzi 1, 43100 Parma, Italy
}

Received: 2 December 2006. Accepted: 2 January 2007

\begin{abstract}
Urban areas are increasing at a rate much higher than human population growth in many part of the world; actually more than 73 towns in the world are larger than $1000 \mathrm{~km}^{2}$. The European Environmental Agency indicates an urban area average growth rate, over the last 20 years, of $20 \%$.

The urbanization process, and the consequent soil sealing, determines not only the losses of the ecological functions of the soil, but also a variation of the energy budget of land surfaces, that affect the microclimatic conditions (heat islands). The alteration of the energy budget are determined by the variations of albedo and roughness of surfaces, but especially by the net losses of evapotranspirating areas. In the present research we have assessed the variation of Parma territory energy budget, induced by the change in land use over the last 122 years. The urban area increase between 1881 and 2003 was $535 \%$.
\end{abstract}

Key-words: urbanization, soil sealing, heat island, climate change, evapotranspiration.

\section{Introduction}

Land use change and land cover change are recognized among the causes of global warming. Deforestation, urban sprawl, agriculture, and other human influences have substantially altered and fragmented our landscape. These kind of disturbance of the land can change the global atmospheric concentration of carbon dioxide, the main heat-trapping gas, as well as affect local, regional, and global climate by changing the energy balance on Earth's surface (Marland et al., 2003). In particular, the influence of urbanization on climate has been well documented (Landberg, 1981; Kukla et al., 1986; Karl et al., 1988; Changon, 1992; Gallo et al., 1993), and because more than $50 \%$ of the human population lives in cities, there is an increasing interest in this process as an important contributor for global warming.

The Urban Heat Islands (UHI) are one of the most known effect of urbanization on climate and have been studied extensively (Atkinson, 1985; Oak,1995; Ben-Dor and Saaroni,
1997). Extensive urbanized surfaces modify the energy and water balance processes and influence the dynamics of air movement (Oke, 1987), determining an increase in the air temperature over the core of the town with respect to the surrounding areas, and the reduction of Diurnal Temperature Range (Gallo et al., 1996). Rao (1972) was the first to demonstrate that urban areas could be identified from the analyses of thermal infrared data acquired by a satellite, while researches conducted on land surface temperature using NOAA AVHRR data, demonstrated that the partitioning of sensible and latent heat fluxes, was a function of varying surface soil water content and vegetation cover (Owen et al., 1998).

The main effect of urbanization on climate is probably realized trough the sealing of soils, that prevent the possibility for these areas to store and release water with evapotranspiration. We have to consider that typically, on a temperate summer day, 4-6 kWh of net solar radiation would fall on each $1 \mathrm{~m}^{2}$. On sealed surfaces most of this energy is converted into sen- 
sible heat, bringing about massive convection, whereas on functional vegetation solar radiation is dissipated harmlessly through water evapotranspiration (Pokorny, 2001).

Urbanization process in the world is constantly increasing, as a results of demographic growth, change in life style and especially as a result of the new global economy (Cohen, 2004). Even in Europe, where the population is substantially stable, there is a continuous increase of the urbanized areas. Over the past 20 years the extent of builtup area in many western and eastern European countries has increased by some $20 \%$ and far exceeds the rate of population growth in the EU over the same period (6\%) (EEA, 2002). In Germany, for example, total land taken for built-up areas, including transport infrastructure, increased from $350 \mathrm{~m}^{2}$ per person in 1950 to $508 \mathrm{~m}^{2}$ per person in 1999 and the average area for living increased from $15 \mathrm{~m}^{2}$ per person in the 1950 to $38 \mathrm{~m}^{2}$ per person in 1995 (Dosch and Beckmann, 2000).

The aim of this research is to evaluate the urban growth of Parma municipality during the last 122 years and to provide an estimate of the effects of these change on the energy budget of the territory.

\section{Materials and methods}

\subsection{Study area}

The research was carried out in Parma, a medium size Northern Italian town, sited on the margin between Po valley and the Appennine. The main geographic feature of Parma and its municipality are presented in Figure 1.

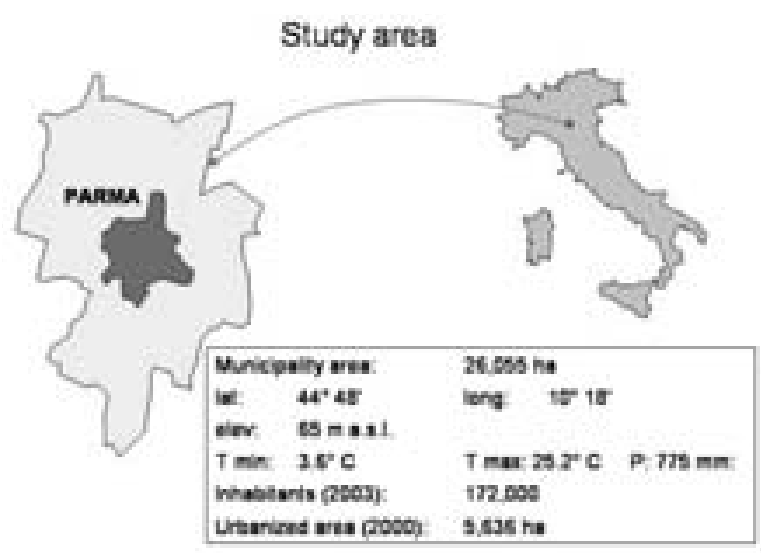

Figure 1. Main geographic feature of the study area.
Table 1. Sources of geographic data used for the urbanization process analysis.

\begin{tabular}{ll}
\hline Period & Source of data \\
\hline 1881 & Geographic militar institute (IGM) map \\
1960 & Geographic militar institute (IGM) map \\
1976 & Regional land use map \\
1994 & Regional technical map \\
2003 & Quick Bird images \\
2030 & Forecast from urban planning documents \\
\hline
\end{tabular}

\subsection{The assessment of urban area growth}

The assessment of temporal variation of urbanized area in Parma municipality has been realized using different sources of geographic data (Tab. 1). All the maps or aerial photos were georeferenced, corrected and digitized using the ArcGIS 9.0 software; the same software was used to perform the spatial analysis and to calculate the extension of the urban area.

The evaluation of vegetated area was carried out with ENVI software and the MIVIS images, calculating the NDVI index on three sample areas for each urbanization phase; a NDVI value of 0.5 was used as threshold to discriminate vegetated and non vegetated areas, within the urban environment.

\subsection{The energy balance model}

The purpose of the proposed approach was to define the temporal variation of the amount of energy dissipated as sensible heat flux, in ground heat flux, latent heat flux and the emitted long wave radiation, as a result of the land use change.

The amount of radiation absorbed by different surfaces and by the entire investigated area, at given time, have been calculated according to:

$$
\mathrm{R}_{\mathrm{abs}}=\alpha_{\mathrm{S}}\left(\mathrm{S}_{\mathrm{b}}+\mathrm{S}_{\mathrm{d}}\right)+\alpha_{\mathrm{L}} \mathrm{L}
$$

where $\alpha_{S}$ and $\alpha_{L}$ are the absortivities in the solar and thermal waveband, $S_{b}$ and $S_{d}$ are the direct and diffuse solar radiation and $\mathrm{L}$ is the incoming long wave radiation.

The solar radiation in Parma, at different date, have been estimated using the following equations, described in Campbell and Norman (1998):

$$
\begin{gathered}
\mathrm{S}_{\mathrm{b}}=\cos \Psi\left[\mathrm{S}_{\mathrm{po}} \exp (-a-\tau m)\right] \\
\mathrm{S}_{\mathrm{d}}=\mathrm{S}_{\mathrm{po}} \cos \Psi[1-\exp (-a-\tau m)]
\end{gathered}
$$



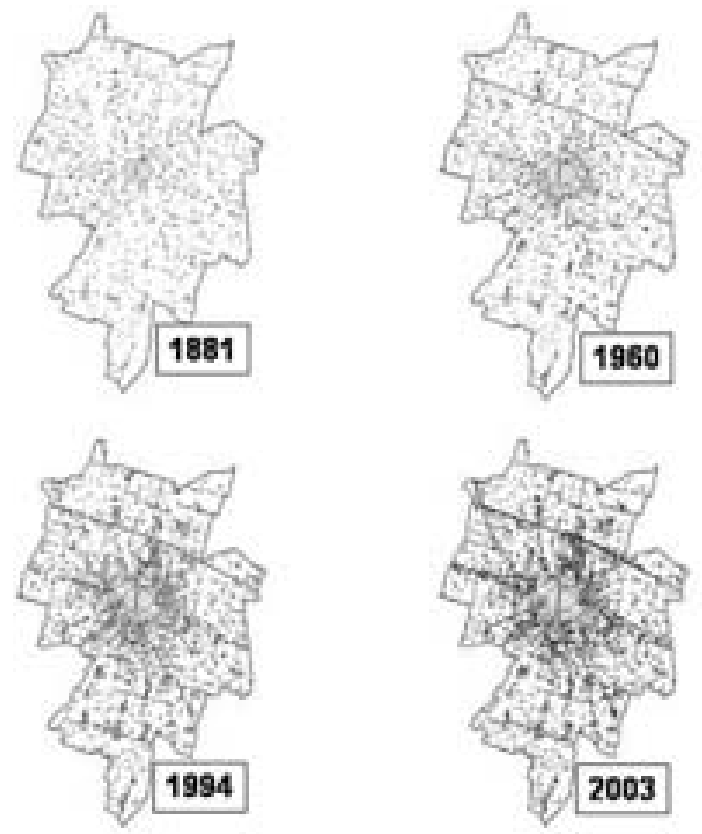

where $\mathrm{S}_{\mathrm{po}}$ is the solar costant, $\Psi$ is the solar zenith angle, $a$ is a coefficient related to wavelengths strongly absorbed by the atmosphere ( $a$ $=0.078), \tau$ is an atmospheric turbidity coefficient ( $\tau=0.077$ for clear sky) and $m$ is the optical air mass number, depending on the path of the solar beam trough the atmosphere. The incoming long wave radiation (L) have been estimated from ten years average air temperature, applying the Stefan-Boltzmann law.

In order to calculate the absorpivities of the solar radiation, it has been necessary to know the albedo of different surfaces; this values and the emissivities of different surfaces were derived from researches of different authors (Morgan et al., 1977; Ryszkowski and Kędziora, 1987) and are indicated in Table 2.

In order to discriminate the latent heat (LE),

Table 2. Albedo of different surfaces.

\begin{tabular}{lc}
\hline Surfaces & Albedo \\
\hline Light density residential & 0.20 \\
Medium density residential & 0.23 \\
High density residential & 0.25 \\
Parks & 0.16 \\
Industrial area & 0.26 \\
Freeway & 0.30 \\
Bare soil & $0.15-0.19$ \\
Winter wheat & $0.17-0.23$ \\
Alfalfa & $0.19-0.22$ \\
\hline
\end{tabular}

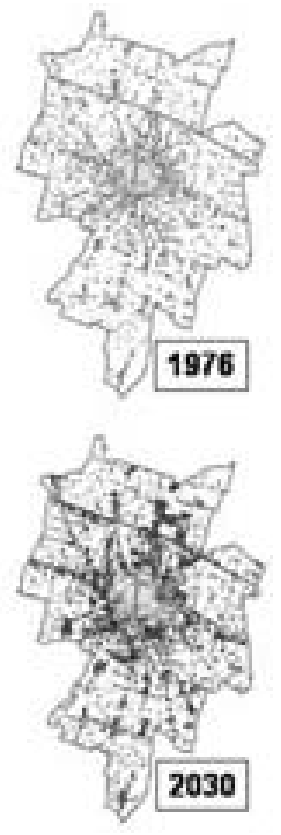

Figure 2. Expansion of Parma urban area between 1881 and 2003.

sensible heat $(\mathrm{H})$, ground heat $(\mathrm{G})$ fluxes and the emitted long wave radiation $\left(\mathrm{L}_{\mathrm{e}}\right)$, the energy budget have been calculated:

$$
\mathrm{R}_{\mathrm{abs}}-\mathrm{H}-\mathrm{G}-\mathrm{LE}-\mathrm{L}_{\mathrm{e}}=0
$$

Evapotranspiration, necessary to determine the latent heat term (LE), was calculated on hourly base, applying the ET model (Donatelli et al., 2006). The soil water balance was calculated on monthly base, applying the BIL3 model (AA.VV., 1990) on ten years series of meteorological data, and using the alfalfa and wheat crop coefficient and $200 \mathrm{~mm}$ soil water capacity.

\section{Results and discussion}

\subsection{Urban area growth}

Data on growth of urban area are shown in Figure 2. The rate of urbanization process was very high in the period $1960-1976$, caused by the fast economic growth followed the second world war and by migration of people from the rural areas and from Southern Italy. However the analysis of other periods (1994-2003) and the comparison of data on the expansion of urban area with the population increase (Fig. 3), showed a weak correlation. This behaviour can be explained considering further driving forces 


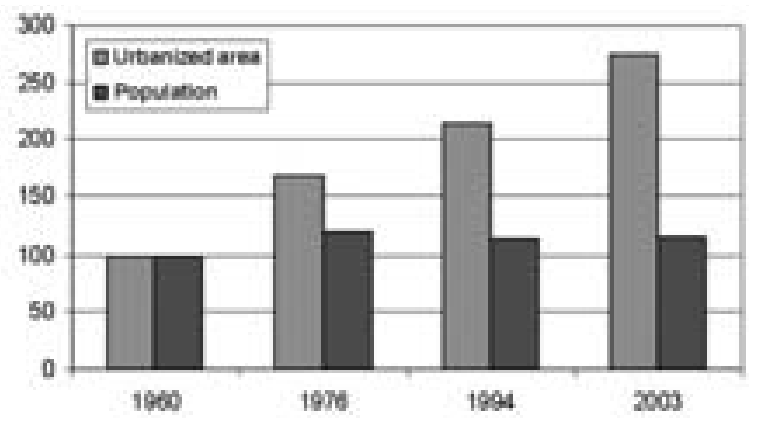

Figure 3. Comparison between urban and population increase.

involved in the process, other than population increase, such as the change in the needs and structure of the society and speculative pressures (Cohen, 2004).

\subsection{Energy balance}

The short and long wave radiation absorbed by different surfaces during the day, were calculated for the fifteenth day of each month (Tab. 3); all the calculation were based on clear sky situation. The comparison between measured and estimated short wave solar radiation, for the year 2000, is presented in Figure 4. The variation in quantity of energy absorbed by different surfaces was limited, with the values ranging between 35.4 and $40.2 \mathrm{MJ} \mathrm{m}^{-2} \mathrm{~d}^{-1}$. A weighted average of this elemental data was used to define the radiation absorbed by the urban area and the rural area.

Monthly and daily data on potential and actual evapotranspiration are presented in Table

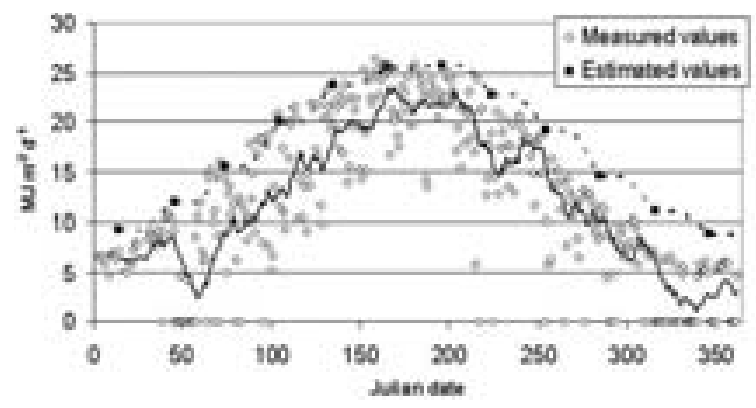

Figure 4. Comparison of measured and estimated short wave solar radiation for the year 2000 .

Table 3. Estimate of short and long wave radiation absorbed by different surfaces the fifteenth day of each month of the year.

\begin{tabular}{lcccc}
\hline & \multicolumn{4}{c}{$M J m^{-2} d^{-1}$} \\
& alfalfa & urban & parks & freeway \\
\hline Jan & 20.5 & 19.8 & 21.1 & 19.0 \\
Feb & 26.6 & 25.6 & 27.5 & 24.5 \\
Mar & 34.8 & 33.3 & 36.0 & 31.8 \\
Apr & 44.9 & 42.9 & 46.5 & 40.6 \\
May & 53.6 & 51.2 & 55.5 & 48.8 \\
Jun & 57.4 & 54.8 & 59.3 & 51.9 \\
Jul & 57.5 & 55.0 & 59.5 & 52.6 \\
Aug & 52.1 & 49.0 & 53.0 & 46.8 \\
Sep & 44.3 & 41.1 & 44.3 & 39.2 \\
Oct & 34.1 & 31.1 & 33.5 & 29.8 \\
Nov & 26.2 & 23.8 & 25.4 & 22.8 \\
Dec & 20.2 & 18.9 & 20.2 & 18.3 \\
\hline
\end{tabular}

4; daily data were used to calculate a simplified energy balance, where from the differences between radiation absorbed (Rabs) and the latent heat (LE), it was estimated a global term

Table 4. Monthly and daily potential and effective evapotranspiration of winter wheat and alfalfa.

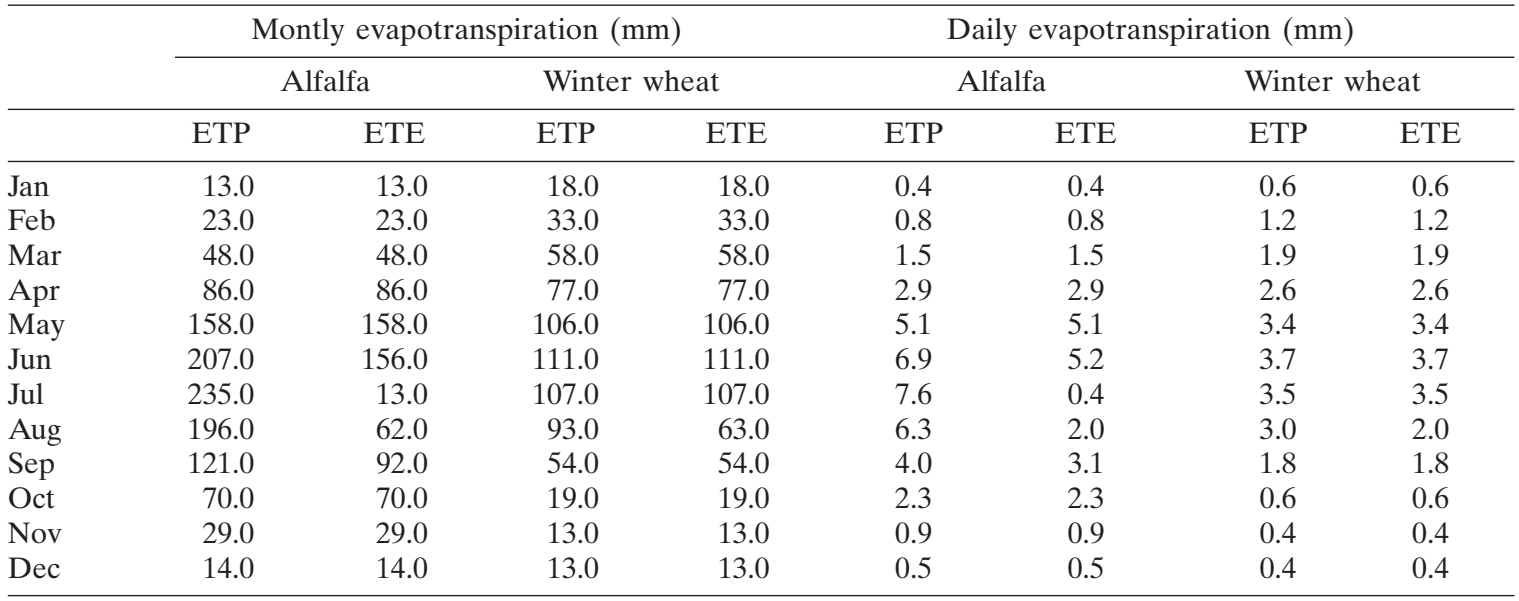



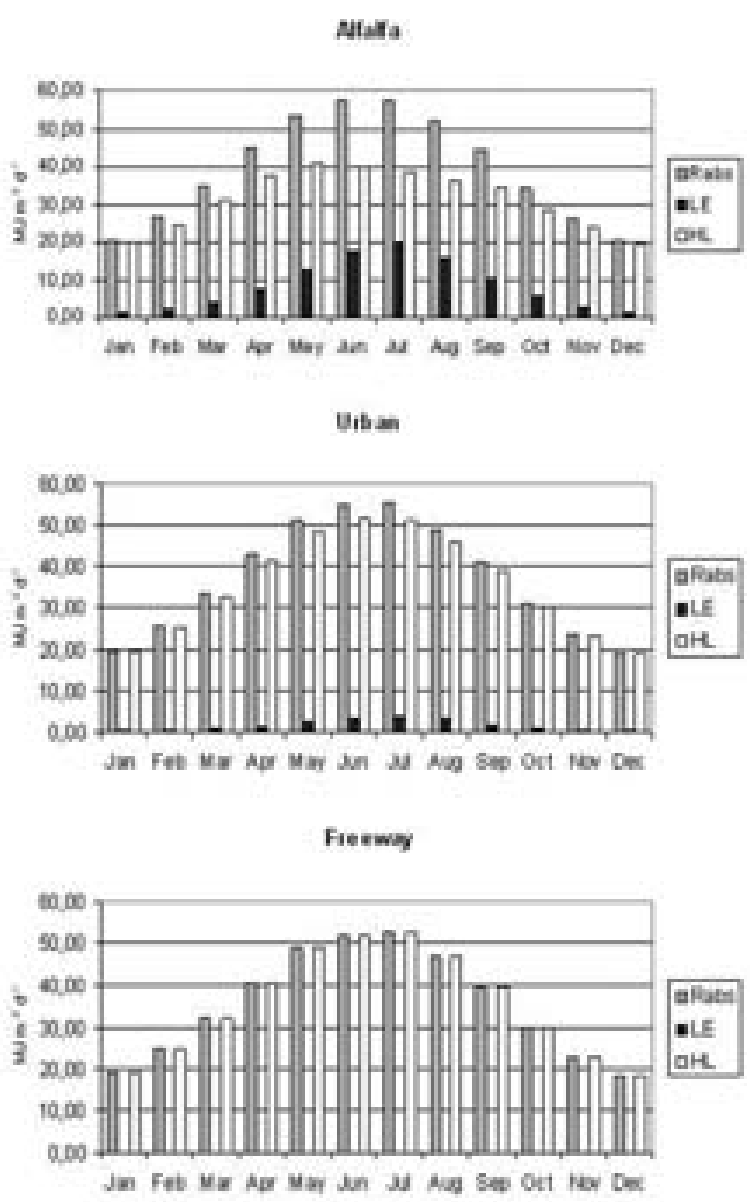

Figure 5. Simplified energy balance applied to different surfaces.

(HL) that includes sensible heat, ground heat and the emission of long wave radiation (Fig. 5 ), while the hourly evapotranspiration for a selected date, estimated with the ET model, was used to calculate a more detailed energy balance.

In Figure 6 are shown the graph of the energy balance of $1 \mathrm{~m}^{2}$ of alfalfa field and $1 \mathrm{~m}^{2}$ of urban area (completely sealed), for the hour 12.00-13.00 of the $15^{\text {th }}$ of June. The amount of radiation absorbed by the two land uses is similar; the alfalfa field absorbed $4,6 \%$ more energy, due to differences in albedo. The largest differences, of course, concern the latent heat term, that is practically equal to 0 in the sealed area; this determine important differences also in the other terms of the energy model balance, such as the sensible heat fluxes and the emission of long wave radiation. Sensible heat flux + ground

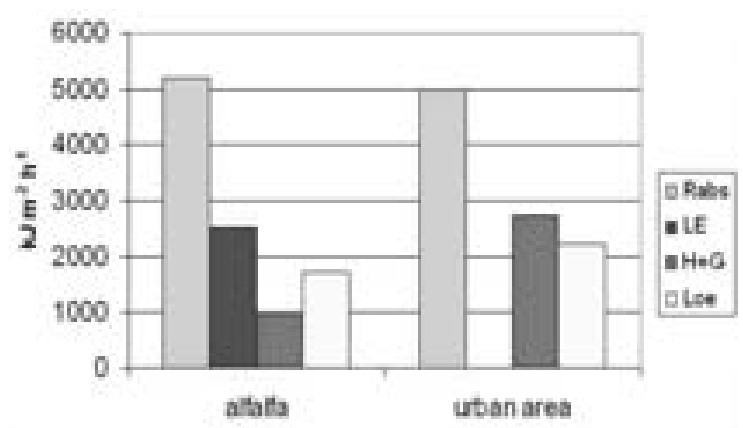

Figure 6. Energy balance of alfalfa and urban area (1ha, $12.00-13.00$ of $165^{\text {th }}$ DOY).

heat flux and long wave radiation, that directly affect the microclimate, are respectively $185 \%$ and $29 \%$ higher in the urbanized area. This data is in agreement with the results of other researches on urban areas (Lamptey et al., 2005; Morgan et al., 1977).

The upscaling of this data allowed to switch from 1 ha of land use model, into a more real world. These data were applied to the Parma municipality, tacking into account the variations in land use between 1881 and 2003. Furthermore territory is a complex mosaic of land use, and at least, of evapotranspirating and non evepotranspirating surfaces. The estimates of the fraction of evapotranspirating surfaces, within the various urban expansion areas, gave the results presented in Table 5 .

The results of the energy budget calculation, based on the $165^{\text {th }}$ DOY, for the five different periods is reported in Figure 7. The simulation was based on the assumption of constant climate over the investigated period.

As a result of $13 \%$ reduction of energy dissipated by latent heat, the sensible heat+ground heat and the emitted long wave radiation increased respectively by $7 \%$ and $16 \%$.

The implication of urbanization on local climate are well known and already discussed in the introduction. A prove of UHI effect for Par-

Table 5. Fraction of vegetated areas within the areas of urban expansion during different periods.

\begin{tabular}{lc}
\hline Period & Fraction of vegetated area \\
\hline Untill 1881 & 0.18 \\
$1881-1960$ & 0.26 \\
$1960-1976$ & 0.28 \\
$1976-1994$ & 0.29 \\
$1994-2003$ & 0.26 \\
\hline
\end{tabular}




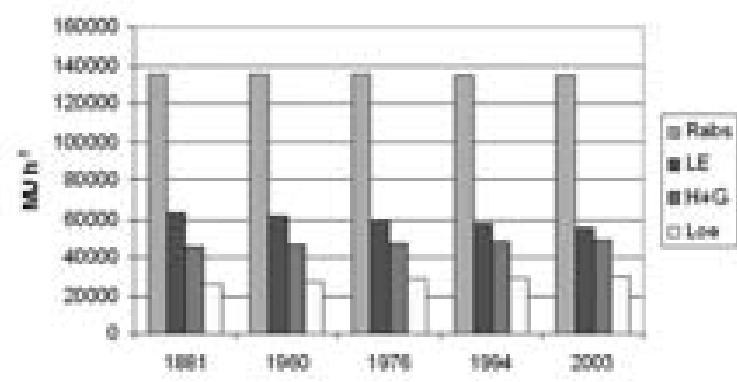

Figure 7. Variation of the energy balance of Parma municipality between 1881 and 2003 .

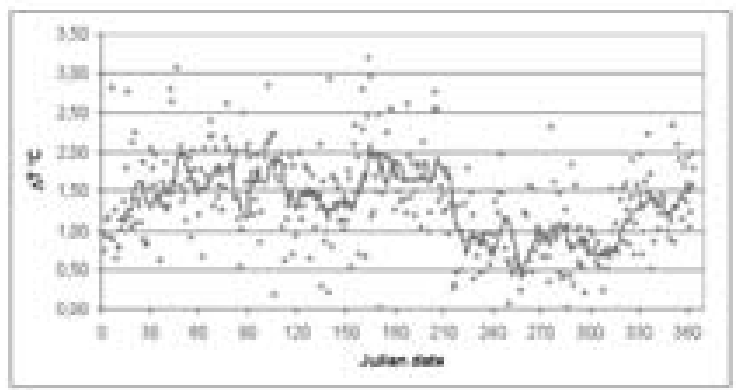

Figure 8. Evaluation of $\Delta \mathrm{T}^{\circ} \mathrm{C}$, related to Urban Heat Island, in Parma during 1999. The red line represent the mobile average calculated over 10 days.

ma is given by the comparison between values of maximum air temperature within the town centre and a suburban area (San Pancrazio Fig. 8). From these data, referred to 1999, it is possible to show an increase in $\Delta \mathrm{T}$ between urban and suburban area. Analysing the mobile average it is possible to recognize different intensity of UHI during the year; the highest $\Delta \mathrm{T}$ occur in the summer season, associated to the high incoming solar radiation, and in winter, probably determined by the massive household heating system in the town.

\section{Conclusions}

Land use change, and in particular the urbanization process, affecting the energy balance of surfaces, can determine important effects on the local climate. Within the Parma municipality, the increase of urban areas occourred between 1881 and 2003 was $535 \%$ and caused on average, a reduction of $0.1 \%$ per year, of the solar energy dissipated by evapotranspiration and a consequent increase of sensible heat.

\section{References}

AA.VV. 1990. Caratteristiche climatiche agronomiche e dei suoli per la stima del bilancio idrico in EmiliaRomagna. Collana "Orientamenti Geomorfologici ed Agronomico-Forestali”, Pitagora, 89 pp.

Atkinson B.W. 1985, The Urban Atmosphere. Cambridge University Press, Cambridge, MA, 89 pp.

Ben-Dor E., Saaroni H. 1997. Airborne video thermal radiometry as a tool for monitoring microscale structures of the urban heat island. Int. J. Remote Sensing, 1997, 18, 14:3039-3053.

Campbell G.S., Norman J.M. 1998. An introduction to Environmental Biophysics. Springer, 286 pp.

Changon S.A. 1992. Inadvertent weather modification in urban areas: Lessons for global climate change. Bull. Amer. Meteor. Soc., 73:619-627.

Cohen B. 2004. Urban Growth in Developing Countries: A Review of Current Trends and a Caution Regarding Existing Forecasts. World Development, vol. 32, 1:23-51.

Donatelli M., Bellocci G., Carlini L. 2006. Sharing knowledge via software components: Models on reference evapotranspiration. Europ. J. Agronomy, 24:186-192.

Dosch F., Beckmann G. 2000. Der Flächenverbrauch in Deutschland hat sich intensiviert. In: Bundesamt für Bauwesen und Raumordnung.

EEA 2002. Environmental signals 2002 - Chapter Agriculture and transport, Environmental assessment report No. 8, European Environment Agency. Official Publications of the European Communities, Luxembourg.

Gallo K.P., Easterling D.R., Peterson T.C. 1996. The influence of land use/land cover on climatological values of the diurnal temperature range. Journal of Climate, 9:2941-2944.

Karl T.R., Diaz H.F., Kukla G. 1988. Urbanization: Its detection and effect in the United States climate record. J. Climate, 1:1099-1123.

Kukla G., Gavin J., Karl T.R. 1986. Urban warming. J. Climate Appl. Meteor., 25:1265-1270.

Lamptey B.L., Barron E.J., Pollard D. 2005. Impacts of agriculture and urbanization on the climate of the Northeastern United States. Global and Planetary Change, 49:203-221.

Landsberg H.E. 1981. The Urban Climate. Academic Press, 275 pp.

Marland G., Pielke R.A., Appsc M., Avissar R., Betts R.A., Davis K.J., Frumhoff P.C., Jackson S.T., Joyce L.A., Kauppi P., Katzenberger J., MacDicken K.G., Neilsonm R.P., Niles J.O., Niyogi D.S., Norby R.J., Pena N., Sampsonq N., Xuer Y. 2003. The climatic impacts of land surface change and carbon management, and the implications for climate-change mitigation policy. Climate Policy, 3:149,157.

Morgan D., Myrup L., Rogers D., Baskett R. 1977. Microclimates within an urban area. Annals of the Association of American Geographer, 67:55-65. 
Oak T. R. 1995, The heat island of the urban boundary layer: characteristics, causes and effects. In: Cermak J.E., Davenport A.G., Plate E.J., Viegas D.X., (eds.): Wind Climate in Cities, 81-107. NATO ASI series (Dordrecht: Kluwer Academic Publishers).

Oke T.R. 1987. Boundary layer climates (2nd ed.). Methuen, London, 435 pp.

Owen T.W., Carlson T.N., Gillies R.R. 1998. An assessment of satellite remotely-sensed land cover parameters in quantitatively describing the climatic effect of urbanization. International Journal of Remote Sensing, 19:1663-1681.

Ryszkowski L., Kędziora A. 1987. Impact of agricultural landscape structure on energy flow and water cycling. Landscape Ecology, 2:85-94.

Xiao-Ling C., Hong-Mei Z., Ping-Xiang L., Zhi-Yong Y. 2006. Remote sensing image-based analysis of the relationship between urban heat island and land use/cover changes. Remote Sensing of Environment, in press. 